Luc Perreault MD, Denis Vézina MSc, Ken Roberts PhD, Robert Baillargeon MD FRCP

\title{
Low-dose sufentanil in major surgery
}

The purpose of this study was to assess the efficacy of sufentanil $1 \mu \mathrm{g} \cdot \mathrm{kg}^{-1}$ during $\mathrm{N}_{2} \mathrm{O} \cdot \mathrm{O}_{2}$ and intermittent isoflurane anaesthesia in major non-cardiac surgery. Thirty-one patients $(18$ females, 13 males; mean age $47 \mathrm{yr}$ ), undergoing cholecystectomy received a $/ \mu \mathrm{g} \cdot \mathrm{kg}^{-1}$ bolus of sufentanil before the induction of anaesthesia with thiopentone. On average, three sufentanil increments were administered, to a total (bolus + maintenance) dose of $1.5 \mu \mathrm{g} \cdot \mathrm{kg}^{-1}$. Cardiovascular stability was not achieved in eleven patients who then were given isoflurane. The arterial pressure decreased after sufentanil ( $P$ $<0.05$ ), reaching a nadir (mean $108165 \mathrm{mmHg}$, heart rate 63 bpm) at one minule post-incision. Clinically important hypertension or hypotension did not occur in any patient. One patient, receiving beta-blocker therapy, required atropine to control bradycardia. Postoperative respiratory depression did not occur in patients who received less than one $\mu \mathrm{g} \cdot \mathrm{kg}^{-1} \cdot \mathrm{hr}^{-1}$ with the last increment being given more than 20 minutes before the end of anaesthesia. Slight respiratory depression in the recovery room was reported in one patient, who had received a total of $1.3 \mu \mathrm{g} \cdot \mathrm{kg}^{-1} \cdot \mathrm{hr}^{-1}$ of sufentanil, and the last sufentanil increment $24 \mathrm{~min}$ before the end of surgery. The most frequently reported side-effects were nausea (35 per cent) and vomiting (23 per cent). Induction, maintenance and recovery from anaes. thesia were rated as "good" in 87, 87, and 74 per cent of the cases, respectively, and "satisfactory" in the remainder. We conclude that this technique is valuable to assure good protection of the cardiovascular system without undue respiratory depression during recovery.

Le but de cette étude était d'évaluer l'efficacité du sufentanil à la dose de I microgramme par kilogramme en association avec protoxyde d'azoteloxygène et occasionnellement isoflurane d la

\section{Key words}

ANAESTHETICS, INTRAVENOUS: sufentanil; ANAESTHETIC TECHNIQUES: balanced anaesthesia.

From the Department of Anaesthesia and the Research Center, Maisonneuve-Rosemont Hospital, University of Montreal, Montreal, Quebec.

Address correspondence to: Dr. Luc Perreault, Department of Anaesthesia, Maisonneuve-Rosemont Hospital, 5415 boul. de l'Assomption, Montreal, Quebec HIT 2M4.

This study was supported by a grant from Janssen Pharmaceutica Canada Ltd. concentration de 0.5 pour cent dans la chirurgie majeure non cardiaque. Trente-et-un sujets, 18 femmes et 13 hommes dont l'áge moyen était de 47 ans devant subir une cholécystectomie ont resu I $\mu \mathrm{g} \cdot \mathrm{kg}^{-1}$ de sufentanil en bolus avant l'induction de. l'anesthésie avec thiopentone. Le maintien de l'anesthésie s' est fait avec protoxyde d' azote et oxygène, et des bolus d' appoint de sufentanil pour maintenir la stabilité des signes vitaur. En moyenne, les malades ont eu besoin de trois bolus d'appoint pour une dose totale de sufentanil de $1,5 \mu \mathrm{g} \cdot \mathrm{kg}^{-1}$. Onze sujets $n$ 'ont pas répondu adéquatement au sufentanil et ont dû recevoir de l'isoflurane en inhalation. A la suite de l'administration de sufentanil, on a observé une baisse de la pression artérielle qui a atteint un nadir une minute après l'incision (moyenne 108165 $\mathrm{mmHg}$, fréquence cardiaque $63 / \mathrm{min}$ ). Dans aucun cas l'hypertension ou l'hypotension n'ont été considérées comme dommageables. Un malade recevant des substances bêta-bloquantes a dû recevoir de l'atropine pour contrer une bradycardie trop intense. Une légère dépression respiratoire a été observée au réveil chez un malade qui avait reçu une dose totale de sufentanil de $1,3 \mu \mathrm{g} \cdot \mathrm{kg}^{-1} \cdot \mathrm{hr}^{-1}$ et dont le dernier bolus d'appoint de sufentanil a été administré 24 min avant la fin de la chirurgie. La dépression respiratoire a répondu à l'administration de naloxone. Les effets secondaires les plus fréquemment observés ont éré les nausées ( 35 pour cent) et les vomissements (23 pour cent). L'induction, le maintien et le réveil ont été jugés "bons" dans 87, 87 et 74 pour cent des cas respectiverent et les autres sujets ont été jugés "satisfaisants». Cette technique s'est avérée adéquate pour assurer une bonne protection du système cardiovasculaire sans provoquer de dépression respiratoire indésirable durant la phase de réveil.

Fentanyl and sufentanil have been used extensively in cardiac surgery. Their efficacy in protecting the cardiovascular system against noxious adrenergic reaction has been demonstrated ${ }^{1-3}$ but the doses used were comparatively high $-5-10 \mu \mathrm{g} \cdot \mathrm{kg}^{-1}$. The purpose of this study was to evaluate the efficacy of sufentanil in a dose of 1 $\mu \mathrm{g} \cdot \mathrm{kg}^{-1}$ in major non-cardiac surgery in providing stable cardiovascular variables during surgery, rapid recovery from anaesthesia and minimal respiratory depression in the recovery room. Bolus increments of $10-25 \mu \mathrm{g}$ and the occasional addition of 0.5 per cent isoflurane were used according to the duration of the surgery and the response of the patient to surgical stimulation. 
TABLE I Demographic data

\begin{tabular}{|c|c|c|c|c|c|c|}
\hline & \multicolumn{2}{|c|}{ Without isoflurane } & \multicolumn{2}{|c|}{ With isoflurane } & \multicolumn{2}{|c|}{ All patients } \\
\hline & $\%$ & $(n)$ & $\%$ & $(n)$ & $\%$ & $(n)$. \\
\hline ASA class 1 & 40 & (8) & 36 & (4) & 39 & (12) \\
\hline 2 & 40 & (8) & 55 & (6) & 45 & (14) \\
\hline 3 & 20 & (4) & 9 & (1) & 16 & (5) \\
\hline Age $<30$ & 15 & (3) & 36 & (4) & 23 & (7) \\
\hline $31-59$ & 40 & (8) & 45 & (5) & 42 & (13) \\
\hline$>60$ & 45 & (9) & 18 & (2) & 35 & (11) \\
\hline Mean \pm SEM $^{*}$ (years) & \multicolumn{2}{|c|}{$49.3 \pm 3.5$} & \multicolumn{2}{|c|}{$44.0 \pm 5.2$} & \multicolumn{2}{|c|}{$47.4 \pm 2.9$} \\
\hline $\operatorname{Sex} M$ & 40 & (8) & 45 & (5) & 42 & (13) \\
\hline$F$ & 60 & (12) & 55 & (6) & 58 & (18) \\
\hline Height (cm, mean \pm SEM) & \multicolumn{2}{|c|}{$164.3 \pm 2.1$} & \multicolumn{2}{|c|}{$166.4 \pm 2.2$} & \multicolumn{2}{|c|}{$165.0 \pm 1.5$} \\
\hline Weight (kg, mean \pm SEM) & \multicolumn{2}{|c|}{$65.4 \pm 2.5$} & \multicolumn{2}{|c|}{$77.2 \pm 5.3$} & \multicolumn{2}{|c|}{$69.6 \pm 2.7$} \\
\hline
\end{tabular}

*SEM $=$ standard error of the mean.

TABLE II Perioperative data

\begin{tabular}{lllll}
\hline & Without isoflurane & & With isoflurane & All patients \\
\hline $\begin{array}{l}\text { Duration of surgery (min) } \\
\text { Mean } \pm \text { SEM* }\end{array}$ & $\begin{array}{l}80.8 \pm 7.1 \\
\text { Range }\end{array}$ & NSt & $\begin{array}{l}90.3 \pm 10.1 \\
54-172\end{array}$ & $\begin{array}{l}84.1 \pm 5.8 \\
42-177\end{array}$ \\
$\begin{array}{l}\text { Duration of anaesthesia (min) } \\
\text { Mean } \pm \text { SEM }\end{array}$ & $100.2 \pm 7.5$ & & & \\
Range & $62-194$ & NS & $75-189$ & $102.7 \pm 5.9$ \\
$\begin{array}{l}\text { Blood loss (ml) } \\
\text { Mean } \pm \text { SEM }\end{array}$ & & & & $62-194$ \\
Range & $232.6 \pm 28.6$ & NS & $259.1 \pm 38.0$ & $242.3 \pm 22.6$ \\
\hline
\end{tabular}

*SEM = standard error of the mean.

†NS $=$ not significant $(P>0.05)$.

\section{Methods}

The protocol was approved by the hospital ethics committee and all patients entering the study gave written informed consent.

Thirty-one patients (Table I), 18 females and 13 males, ASA physical status I, II or III, aged 18 to $70 \mathrm{yr}$, undergoing elective cholecystectomy, participated in the study. Perioperative data are shown in Table II. Concurrent medications were continued during the perioperative period as clinically indicated. All patients received triazolam $0.005 \mathrm{mg}$ to $0.006 \mu \mathrm{g} \cdot \mathrm{kg}^{-1}$ orally the night before the operation and diazepam 0.1 to $0.125 \mu \mathrm{g} \cdot \mathrm{kg}^{-1}$ one hour before the induction of anaesthesia.

The monitoring included continuous ECG and blood pressure readings every minute during induction and every three minutes during maintenance of anaesthesia, using an automatic device (DINAMAP). At the time, routine use of pulse oximetry was not available. Canula- tion of the external jugular vein using a cathlon \# 18 was used to obtain blood samples.

Blood pressure and heart rate values the day before the operation were used as baseline to evaluate the changes in vital signs during anaesthesia. A change of \pm 20 per cent from the baseline was considered disturbing. After a precurarizing dose of pancuronium, I $\mathrm{mg}$, anaesthesia was induced with $I \mu \mathrm{g} \cdot \mathrm{kg}^{-1}$ sufentanil over three to five minutes using the drug diluted in glucose five per cent in $50 \mathrm{ml}$. Then, a sleep dose of thiopentone was given followed by succinylcholine $1.5 \mathrm{mg} \cdot \mathrm{kg}^{-1}$. The trachea was intubated and anaesthesia was maintained with nitrous oxide/oxygen (66/33 per cent). Muscle relaxation was achieved with d-tubocurarine $0.3 \mathrm{mg} \cdot \mathrm{kg}^{-1}$. During maintenance, patients developing cardiovascular instability were given increments of sufentanil $(10 \mu \mathrm{g})$. If the patient failed to respond adequately to three consecutive increments over five minutes, isoflurane 0.5 per cent was 
TABLE III Sufentanil administration

\begin{tabular}{llll}
\hline & Without isoflurane & With isoflurane & All patients \\
\hline $\begin{array}{l}\text { Initial dose } \\
\left(\mu \mathrm{g} \cdot \mathrm{kg}^{-1}\right)\end{array}$ & $1.00 \pm 0.00^{*}$ & $0.99 \pm 0.01$ & $1.00 \pm 0.00$ \\
$\begin{array}{l}\text { Total increment } \\
\left(\mu \mathrm{g} \cdot \mathrm{kg}^{-1}\right)\end{array}$ & $0.56 \pm 0.07$ & $0.53 \pm 0.08$ & $0.55 \pm 0.05$ \\
$\begin{array}{l}\text { Total dose } \\
\left(\text { bolus }+ \text { increment, } \mu \mathrm{g} \cdot \mathrm{kg}^{-1}\right)\end{array}$ & $1.56 \pm 0.07$ & $1.52 \pm 0.07$ & $1.54 \pm 0.05$ \\
$\begin{array}{l}\text { Dosage per hour } \\
\left(\mu \mathrm{g} \cdot \mathrm{kg}^{-1} \cdot \mathrm{hr}^{-1}\right)\end{array}$ & $1.01 \pm 0.33$ & $0.91 \pm 0.24$ & $0.98 \pm 0.30$ \\
\hline
\end{tabular}

*Mean \pm standard error of the mean.

administered to correct blood pressure and pulse rate to within 20 per cent of control.

Plasma concentrations of sufentanil were determined by radioimmunoassay, using the technique described by Michiels et al. ${ }^{4}$ in 20 patients from blood drawn at 2, 5, 7, $10,15,20,30,45,60,75,90,105,120,135$ and $150 \mathrm{~min}$ after the administration of sufentanil. We then attempted to make a correlation between plasma levels of sufentanil and pain reactions (hypertension and/or heart rate higher by 20 per cent from the baseline) during maintenance of anaesthesia and between plasma levels of sufentanil at the time of extubation and the return of consciousness at the end of anaesthesia.

Respiratory depression was considered to be present when the respiratory rate was below eight per minute. The tracheas of patients were extubated when the oropharyngeal reflexes were present after complete reversal of curare and response to verbal command. Nausea and vomiting were considered disturbing when they had to be treated with medication or nasogastric tube. Postoperative analgesia in the post-anaesthesia recovery room (PARR) was evaluated by questionnaire and by the need for analgesic drugs based on the modification of vital signs. The adequacy of recovery and efficacy of respiration in the recovery room were assessed by a research nurse, using the Aldrete PARR evaluation. All patients were also evaluated for (a) time to response to verbal command, (b) time to extubation, (c) time to establish alertness: orientation in four dimensions, (d) time to discharge from PARR: to a maximum score of ten. Awareness was evaluated by the research nurse the day foltowing anaesthesia, using a questionnaire enquiring about the time of the last recollection before anaesthesia, recollection of perioperative events and the time of the first postanaesthesia recollection.

Data are expressed as mean values \pm SEM. Withingroup (all patients; patients not requiring isoflurane; patients requiring isoflurane) changes in cardiovascular variables were assessed using analysis of variance (ANOVA); with subjects and time of observation as factors, utilising data to the "50 minutes post-incision" observa- tion point. Dunnett's test was used to determine which data differed significantly from the control value.

This allowed the comparison of values at nine observation times with the control value. Since the shortest duration of surgery in any patient was $42 \mathrm{~min}$, utilising data to $50 \mathrm{~min}$ post-incision also ensured that all cardiovascular data included in the ANOVA were obtained using automated monitoring devices.

The duration of surgery and the recovery data (time to extubation) were assessed using the Mann-Whitney U-test, or, when proportions were compared, Fisher's Exact test. A one sample Chi-square test was used to assess the investigator's evaluations. The use of "significant" throughout the text denotes statistical significance at the five per cent level $(P<0.05)$.

\section{Results}

\section{Dose of sufentanil}

The doses of sufentanil $\left(\mu \mathrm{g} \cdot \mathrm{kg}^{-1}\right)$ are listed in Table III. The mean time of administration of last increment was $57.9 \pm 5.0 \mathrm{~min}$ (mean $\pm \mathrm{SEM}$ ) from the time of bolus administration. When necessary, isoflurane was administered at a dosage of 0.5 per cent and the mean length of its administration was $25.4 \pm 5.1 \mathrm{~min}$ (mean $\pm S E M$ ).

\section{Cardiovascular stability}

Mean arterial pressure and heart rate are shown in Figures I and 2. A statistically significant decrease in arterial pressure was evident following sufentanil administration, reaching a nadir one minute after incision. After a slight initial increase post-sufentanil administration, the heart rate also decreased significantly, being slowest one minute after incision. Hypotension was not considered to be disturbing in any of the patients. Bradycardia occurred in two patients and was considered to be clinically important and possibly drug-related in one case. This patient had severe coronary insufficiency, was taking beta-blocking drugs and had a heart rate of 48 beats per minute at the control observation. The bradycardia was 


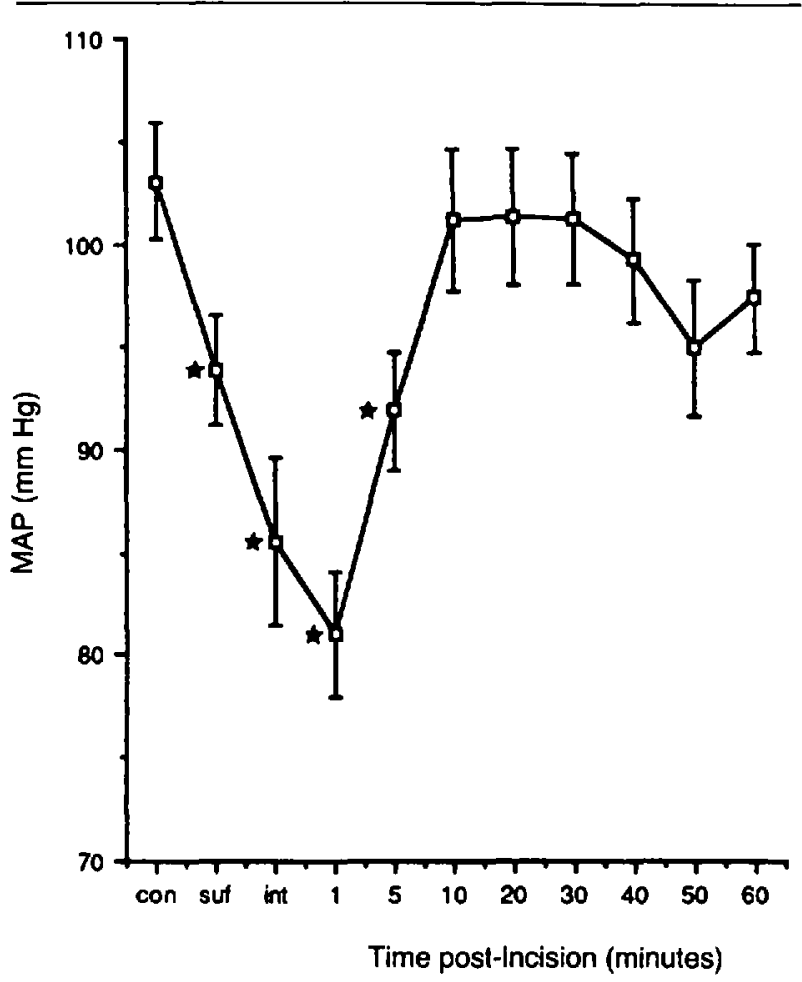

FIGURE I Mean anerial pressure (MAP) measured during surgery, for all patients (mean $\pm \mathrm{SEM}$ ). *Significantly different from control value $(P<0.05)($ con $=$ control, suf $=$ bolus and int $=$ intubation $)$.

exaggerated by sufentanil. The patient responded to two doses of atropine $0.4 \mathrm{mg}$.

\section{Recovery}

Measures of recovery (Table IV) were similar among patients who required isoflurane and those who did not.

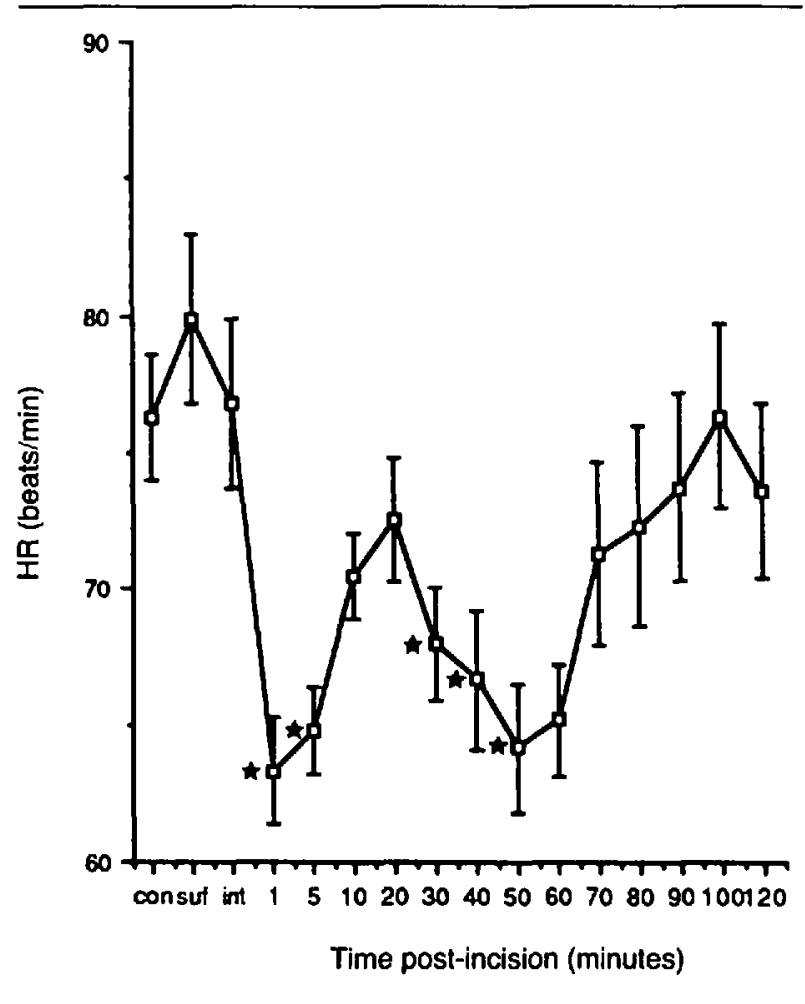

FIGURE 2 Heart rale (HR) measured during surgery, for all patients (mean \pm SEM). *Significantly different from control value $(P<$ 0.05) (con $=$ control, suf $=$ bolus and int $=$ intubation).

Patients remained in the recovery room for $112 \pm 10$ minutes (mean \pm SEM).

Analgesic, antiemetic and anxiolytic requirements were similar among patients who required isoflurane and those who did not. In 71 per cent of the patients, the last recollection was falling asleep. Twenty-six per cent of

TABLE IV Measures of recovery

\begin{tabular}{|c|c|c|c|}
\hline & Without isoflurane & With isoflurane & All patients \\
\hline \multicolumn{4}{|c|}{$\begin{array}{l}\text { Time to response to verbal } \\
\text { commands (min) }\end{array}$} \\
\hline Mean \pm SEM & $8.7 \pm 5.5$ & $8.0 \pm 4.0$ & $8.5 \pm 3.8$ \\
\hline Range & $0-110$ & $0-40$ & $0-110$ \\
\hline \multicolumn{4}{|c|}{ Time to extubation (min) } \\
\hline Mean \pm SEM & $19.5 \pm 8.9$ & $23.8 \pm 10.9$ & $21.0 \pm 6.8$ \\
\hline Range & $0-135$ & $1-104$ & $0-135$ \\
\hline \multicolumn{4}{|c|}{ Time to establish alertness (min) } \\
\hline Mean $\pm S E M$ & $29.2 \pm 8.0$ & $31.0 \pm 8.8$ & $29.8 \pm 5.9$ \\
\hline Range & $6-135$ & $2-97$ & $2-135$ \\
\hline \multicolumn{4}{|c|}{$\begin{array}{l}\text { Time to discharge from recovery } \\
\text { room (min) }\end{array}$} \\
\hline Mean \pm SEM & $111.2 \pm 12.8$ & $115.1 \pm 12.8$ & $112.6 \pm 10.0$ \\
\hline Range & $71-295$ & $67-255$ & $67-295$ \\
\hline
\end{tabular}

Note: All times measured from end of surgery. 
TABLE V Investigator's evaluations

\begin{tabular}{|c|c|c|c|c|c|c|}
\hline & \multicolumn{2}{|c|}{ Without isoflurane } & \multicolumn{2}{|c|}{ With isoflurane } & \multicolumn{2}{|c|}{ All patients } \\
\hline & $\%$ & (n) & $\%$ & (n) & $\%$ & $(n)$ \\
\hline \multicolumn{7}{|l|}{ Last recollection } \\
\hline Joumey to OR & 0 & (0) & 9 & (1) & 3 & (1) \\
\hline In $\mathrm{OR}$ & 35 & (7) & 9 & (1) & 26 & (8) \\
\hline Falling asleep & 65 & (13) & 82 & (9) & 71 & $(22)$ \\
\hline \multicolumn{7}{|l|}{ Next recollection } \\
\hline Post-op, in OR & 5 & (1) & 9 & (1) & 6 & (2) \\
\hline In recovery room & 65 & (13) & 73 & (8) & 68 & (2l) \\
\hline In ward room & 30 & (6) & 18 & $(2)$ & 26 & (8) \\
\hline \multicolumn{7}{|l|}{ Induction } \\
\hline Good & 89 & (17) & 82 & (9) & 87 & $(26)$ \\
\hline Satisfactory & 11 & (2) & 18 & (2) & 13 & (4) \\
\hline Unsatisfactory & 0 & (0) & 0 & $(0)$ & 0 & (0) \\
\hline \multirow[t]{2}{*}{ Not recorded } & & (1) & & & & (I) \\
\hline & & & & & \multicolumn{2}{|c|}{$P<0.001$} \\
\hline \multicolumn{7}{|l|}{ Maintenance } \\
\hline Good & 85 & (17) & 91 & (10) & 87 & (27) \\
\hline Satisfactory & 15 & (3) & 9 & (1) & 13 & (4) \\
\hline Unsatisfactory & 0 & $(0)$ & 0 & $(0)$ & $\stackrel{0}{P}$ & (0) \\
\hline \multicolumn{7}{|l|}{ Recovery } \\
\hline Good & 70 & (14) & 82 & (9) & 74 & (23) \\
\hline Satisfactory & 30 & (6) & 18 & (2) & 26 & (8) \\
\hline \multirow[t]{2}{*}{ Unsatisfaciory } & 0 & (0) & 0 & (0) & 0 & (0) \\
\hline & & & & & \multicolumn{2}{|c|}{$P=0.007$} \\
\hline
\end{tabular}

Note: $P$ values based on one sample chi-square tesl, assuming equal expected frequencies for "good" and "satisfactory" ratings.

patients next remembered being in their room, although 68 per cent recalled being in the recovery room (Table V).

\section{Side effects}

In order to prevent chest wall rigidity the bolus dose was diluted with dextrose and given by slow injection. Using this technique only two patients exhibited rigidity which was rapidly corrected by injection of succinylcholine. One case of drug-related respiratory depression in the recovery room responded to naloxone $0.04 \mathrm{mg}$. The patient had received a total of $1.7 \mu \mathrm{g} \cdot \mathrm{kg}^{-1}$ of sufentanil over $79 \mathrm{~min}\left(1.30 \mu \mathrm{g} \cdot \mathrm{kg}^{-1} \cdot \mathrm{hr}^{-1}\right)$.

The most frequently reported side effects were nausea ( 35 per cent) and vomiting ( 23 per cent) which were disturbing in two patients. Both patients had nausea and vomiting for a period of 12 to 16 hours and had received three and four intra-muscular doses of $50 \mathrm{mg}$ of meperidine. The meperidine was stopped for the first patient and the second received dimenhydrinate $50 \mathrm{mg}$ and needed a nasogastric tube.

\section{Quality of anaesthesia}

Induction, maintenance and recovery were rated by the anaesthetist as good in 87,87 and 74 per cent of cases, respectively (Table $\mathrm{V}$ ).

\section{Plasma dosages}

Twenty patients had plasma concentrations of sufentanil analysed using a radioimmunoassay technique. ${ }^{4}$ Figure 3 shows the plasma concentrations of sufentanil over time expressed as a mean value \pm SEM for all patients. The individual variations in plasma concentrations explain the dispersion of the results and the magnitude of the SEM. Table VI illustrates the plasma concentrations during maintenance of anaesthesia and at the time of recovery. There was no statistically significant difference between steady state of vital signs and pain reaction illustrated by hypertension and elevation of heart rate of more than 20 per cent above the base line.

\section{Discussion}

\section{Blood pressure and heart rate}

There was consistent decrease in blood pressure and heart rate at the induction of anaesthesia which was lowest one minute after incision. This phenomenon has also been 


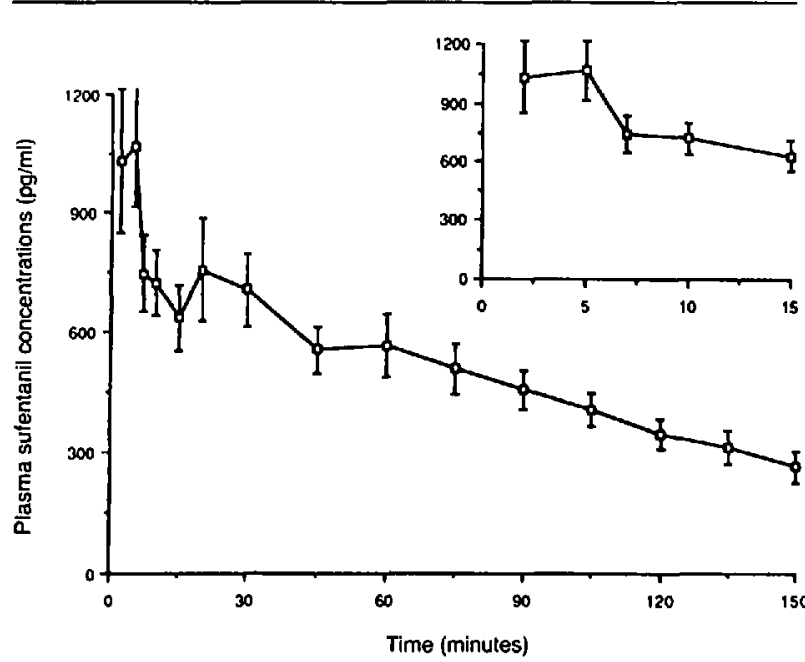

FIGURE 3 Sufentanil plasma concentrations measured during surgery, for all patients (mean \pm SEM).

observed by Murkin. ${ }^{5}$ It appears to be a consequence of the adrenergic blockade produced by sufentanil rather than of histamine release, as reported by Rosow et al. and Flacke et al. ${ }^{6.7}$ This effect seems to be greater than with fentanyl and impairs the compensatory reactions of tachycardia or peripheral vasoconstriction in response to hypotension. The phenomenon is more important in subjects fasting for long periods of time and must be considered carefully in poor-risk patients. Interaction with other anaesthetic induction agents may contribute to a decrease of peripheral resistance and an increase in venous pooling, as reported by Reves concerning the interaction of benzodiazepines and narcotics. ${ }^{8}$

\section{Chest wall rigidity}

Chest wall rigidity has been reported frequently as a side-effect of sufentanil. ${ }^{9-11}$ In our series, decreasing the speed of administration of the initial bolus dose by diluting the total amount in $50 \mathrm{ml}$ of dextrose solution was associated with a negligible incidence of this complication.

TABLE VI Sufentanil plasma concentrations and clinical signs

\begin{tabular}{llll}
\hline & \multicolumn{3}{l}{ Sufentanil concentrations $(p g \cdot m)^{-1}$} \\
\cline { 2 - 4 } Clinical signs & Without isoflurane & With isoflurane & All patients \\
\hline $\begin{array}{c}\text { Steady state } \\
\quad \text { Mean } \pm \text { SEM* }\end{array}$ & $820 \pm 76$ & $642 \pm 51$ & $719 \pm 44$ \\
$\begin{array}{c}\text { Pain reaction } \\
\text { Mean } \pm \text { SEM }\end{array}$ & $861 \pm 106$ & $602 \pm 57$ & $767 \pm 73$ \\
$\begin{array}{c}\text { Recovery } \\
\text { Mean } \pm \text { SEM }\end{array}$ & $413 \pm 60^{*}$ & $394 \pm 74^{*}$ & $404 \pm 46^{*}$ \\
\hline
\end{tabular}

*Significantly different $(P<0.05)$ from levels of steady state and pain reaction.

\section{Time of recovery}

The time of response to verbal command was $8 \pm 3.8 \mathrm{~min}$ after the end of anaesthesia and tracheal extubation was possible after $20 \pm 6.8 \mathrm{~min}$. Alertness was observed at 29 $\pm 5.9 \mathrm{~min}$. The time of recovery was not influenced by administration of isoflurane. The important determinants of the length of the recovery period are the total dosage of sufentanil $\left(\mu \mathrm{g} \cdot \mathrm{kg}^{-1} \cdot \mathrm{hr}^{-1}\right)$ and the time of administration of the last increment.

\section{Respiratory depression}

Respiratory depression in the recovery room is a sideeffect that may be expected after the use of any narcotic anaesthetic. Sufentanil is no exception. ${ }^{12}$ Increasing experience with the drug makes it less frequent, especially when care is taken not to give more than $1 \mu \mathrm{g} \cdot \mathrm{kg}^{-1} \cdot \mathrm{hr}^{-1}$ s and to give the last supplementation of narcotic at least 20 minutes before the end of surgery.

\section{Postoperative analgesia}

Good analgesia was observed during the recovery period even when the patients were completely awake. The need for analgesics occurred $60 \mathrm{~min}$ post-arrival in the recovery room.

\section{Awareness}

No case of awareness was observed in our series, but all patients had received benzodiazepines before anaesthesia. Even with a potent narcotic like sufentanil, there is always the possibility of awareness especially if the agent is used at low doses and benzodiazepine may help to produce amnesia. ${ }^{13,14}$

\section{Plasma concentrations}

Plasma concentrations around $750 \mathrm{pg} \cdot \mathrm{ml}^{-1}$ were sufficient to produce good cardiovascular stability. As illustrated in the plasma dosage study, patients recovered consciousness and spontaneous respiration at plasma concentrations of about $400 \mathrm{pg} \cdot \mathrm{ml}^{-1}$ (Table VI).

\section{Conclusion}

Sufentanil is a potent narcotic agent and is useful in balanced anaesthesia with nitrous oxide and oxygen with or without a halogenated inhalational agent. The dosage used in our series prevented cardiovascular changes during laryngoscopy and intubation and provided relative stability of the vital signs during surgery. The use of repeated boluses of sufentanil in balanced anaesthesia may allow a reduction in the total dosage of sufentanil and concentration of isoflurane and decreases side effects. ${ }^{15}$ The recovery time after sufentanil was relatively short but there was the possibility of respiratory depression in the early recovery period. Spontaneous respiration was possi- 
ble when plasma levels of sufentanil were approximately $400 \mathrm{pg} \cdot \mathrm{ml}^{-1}$.

\section{Acknowledgements}

The authors gratefully acknowledge our research nurse, Mrs. Christiane Côté, for her help in collection of data, search of the literature and revision of the manuscript and Mrs. Sylvie Le Breux for her secretarial support in the preparation of the manuscript.

\section{References}

1 Sebel PS, Bovill JG. Cardiovascular effects of sufentanil anesthesia. Anesth Analg 1982; 61: 115-9.

2 Stanley TH, Berman L, Greene O, Robertson D. Plasma catecholamine and cortisol responses to fentanyl-oxygen anesthesia for coronary artery operations. Anesthesiology 1980; 53: 250-3.

3 Bovill JG, Sebel PS. Pharmacokinetics of high-dose fentanyl: a study in patients undergoing cardiac surgery. Br J Anaesth 1980; 52: 795-802.

4 Michiels $M$, Hendriks $R$, Heykants $J$. Radioimmunoassay of the new opiate analgesics alfentanil and sufentanil. Preliminary pharmacokinetic profile in man. J Pharm Pharmacol 1983; 35: 86-93.

5 Murkin JM. Sufentanil anaesthesia for major surgery: the multicentre Canadian clinical trial. Can J Anaesth 1989; 36: 343-9.

6 Rosow CE, Philbin DM, Keegan CR, Moss J. Hemodynamics and histamine release during induction with sufentanil or fentanyl. Anesthesiology 1984; 60: 489-9I.

7 Flacke JW, Bloor BC, Kripke BJ. Comparison of morphine, meperidine, fentanyl, and sufentanil in balanced anesthesia: a double-blind study. Anesth Analg 1985; 64: 897-910.

8 Reves $J G$. Interaction of diazepines and narcotics. In: Estafanous FG (Ed.). Opioids in Anesthesia. Boston: Butterworth Publishers. 1984, 249-52.

9 Goldberg $M$, Ishak $S$ et al. Postoperative rigidity following sufentanil administration. Anesthesiology 1985; 65: 199-201.
10 Hilberman $M$, Hyer $D$. Potency of sufentanil. Anesthesiology 1986; 64: 665-7.

11 Griffiths $G$. Potency of sufentanil (correspondence). Anaesthesiology 1986; 64: 667-8.

12 Robinson $D$. Respiratory arrest after recovery from anaesthesia supplemented with sufentanil. Can J Anaesth 1988; 35: 101-2.

13 Wong $K C$. Narcotics are not expected to produce unconsciousness and amnesia. Anesth Analg 1983; 62: 625-6.

14 Scharf $M$. Comparative amnesic effects of benzodiazepine hypnotic agents. J Clin Psychiatry 1988; 49: 134-7.

15 Hecker BR, Lake CL, DiFazio CA et al. The reduction in halothane MAC with sufentanil. Anesthesiology 1983; 59: A341. 